\title{
Electronic Marketing in Business-to-Business Markets - User Related Benefits of Sales Configurators
}

\author{
Tommi Mahlamäki \\ Tampere University of \\ Technology \\ tommi.mahlamaki@tut.fi
}

\author{
Kati Stormi \\ Tampere University of \\ Technology \\ kati.stormi@gmail.com
}

\author{
Lauri Saarivuori \\ $\underline{\text { lauri.saarivuori }}$ \\ @gmail.com
}

\author{
Mika Ojala \\ Tampere University of \\ Technology \\ mika.k.ojala@gmail.com
}

\begin{abstract}
Electronic marketing is becoming an integral part of the sales process in business-to-business (B2B) markets. In line with that, sales configurators are emerging as novel applications that help companies engage customer and drive sales. This research investigates the feature related benefits of sales configurator. Our goal is to categorize the benefits and to identify the important ones. In order to reach the goal, personal interviews were conducted and data was gathered through an online questionnaire. Responses from 152 business-to-business customers were analyzed and a factorial model of the feature related benefits of sales configurators was developed. The results show a model with five factors: versatility, configurability, user experience, security, and customizability. Of these, user experience and security were found to be the most important. In light of the this, we suggest that companies emphasize the aspects of user experience in addition to core functionalities when developing sales force automation systems.
\end{abstract}

\section{Introduction}

Many companies are experiencing the so-called customization-responsiveness squeeze [1]. This is the result of the need to offer more customized products and the need to develop, produce, and deliver such products with greater rapidity [1]. The product variety paradox is a similar problem. This means that while organizations offer more product variety and customization in an attempt to increase their sales, paradoxically they end up losing a share of their sales [2]. Sales configurators offer a solution for both of these problems. Sales configurators are sales force automation (SFA) applications or systems designed to help organizations implement the product configuration process [1]. A sales configurator helps create tailored products that match a customer's needs and preferences. A well-implemented sales configurator increases customer satisfaction as well as a company's sales and profitability. However, poor design and implementation may have an opposite effect: a frustrated customer will not buy a massproduced product or a tailor-made product.

Traditional SFA systems are used mainly by individuals in the selling company. Sales configurators, on the other hand, can be used by both customers and sellers. This clear distinction makes the investigation regarding sales configurators needed and relevant for both practitioners and scholars alike.

Studies have shown that SFA use has a direct effect on a salesperson's performance [3]. This means that companies should endorse their employees' use of the system. Yet, little research attention has been paid to the characteristics and benefits these systems provide to an individual user. In addition, the research is often anecdotal or is based on personal interviews.

The objective of this research study is to investigate the feature related, individual level benefits of a sales force automation system: a sales configurator. We aim to address the need for a systematic and quantitative approach to determine the benefits. Moreover, our goal is to categorize the sales configurator benefits and identify the most important ones. Our investigation will focus on individual user level benefits that are linked to the system features.

The paper proceeds as follows: first, we introduce the relevant literature, sales configurators, benefits of SFA and the link between SFA and company performance. The literature review is followed by a description of the study's methods, including those used to collect and analyze the data. Then, the results are presented and conclusions are drawn.

\section{Sales Configurators}

The basic functionality of sales configurators is the configuration process, which is defined as the set of 
activities aimed at translating customer needs into correct and complete product information supporting order acquisition and fulfillment [1].

From the customers' perspective, product configurators are applications that support them in choosing the product solution that best fits their needs from a specific organization's product offering [2]. Product configurators can also be seen as components of sales force automation tools [4]. Product configurators can be stand-alone applications or modules of other applications [2].

The fundamental functions of sales configurators include presenting an organization's product offering, guiding customers in the generation and selection of a product variant, and preventing unfeasible product characteristics from being defined [2]. Additional functionalities may include real-time price information, delivery information, providing sales quotes, and recommending a product solution that can be further altered [2].

A sales or product configurator can deliver multiple benefits. A product configurator enables a better fit between each customer's specific needs and the product solution delivered by the organization. It also prevents the salesperson from developing a basic solution offered to every customer even though a better solution could be available. Using a product configurator also decreases the risk that a customer is not asked about his/her preferences related to important product features. In other words, it does not let the salesperson forget to ask all the necessary questions. In this way, the product configurator also decreases the amount of errors made [5].

\section{Potential Benefits of SFA}

The potential benefits of SFA use have been widely studied. However, the reported results are inconsistent. It has been proven that SFA can provide multiple benefits for an organization and the end customers when used correctly. However, in many implementations, this is not the case.

In this section we want to take a broad look at the literature regarding the possible benefits of SFA. Although the focus our paper is on the individual-level benefits, we introduce benefits on both the organizational and the individual level.

\subsection{Organizational benefits}

The adoption of SFA results in different kinds of benefits for different organizations. This is because SFA involves a wide range of hardware and software solutions that can support cost reductions and/or improve the effectiveness of a company's relationship with its customers [4]. While SFA systems can provide many possible benefits, no organization can realize all of them.

A review of the literature on SFA systems indicates that the potential benefits include reduced costs, enhanced productivity, increased closing rates, better information flow within an organization, elimination of duplicate databases, better collaboration between the sales force and production units, more flexibility with customer services, the ability to share best practices, the ability to reassign leads that have not been acted on, and more effective management of the sales force [6]. Other researchers have provided evidence that SFA technology can increase available selling time and enhance communication, which leads to an increase in the overall quality of the sales effort [7]. Eggert and Serdaroglu [3] found that SFA can increase available selling time, enhance communication, and improve overall sales quality through faster access to relevant and timely information. Morgan and Inks [8] reported that SFA systems promise numerous benefits, such as increased productive selling time, enhanced contact management abilities, and the ability to deliver superior customer value through information sharing across sales, marketing, and customer service personnel.

Research has found that SFA technology can increase the efficiency and effectiveness of the sales force through their ability to enhance communication between the salesperson, the buying organization, and the selling firm [7]. Pullig et al. [9] summarized this very well by noting: "Perhaps the greatest potential of SFA systems is the sharing of contact information and increased coordination across the firm's various customer service functions."

Ultimately, SFA provides companies with the potential to manage their sales force and sales processes more efficiently, to automate and standardize sales activities, and to connect the salesforce with the rest of the organization [6]. Collectively, these attributes can lower costs and increase profits. However, the most important benefit of using SFA systems is the increased quality of a company's relationship with its customers and the ability to deliver more value to its customers.

The benefits stated were reported in just a handful of studies, but it is clear that numerous potential benefits can be gained from using an SFA system. While many researchers have identified the same potential benefits, some more than others, it seems as if most organizations implement an SFA system to either improve productivity or decrease costs. Because a company's main goal is to increase its profitability, most companies seem to focus only on that objective. 
However, profit increases are linked to a company's ability to deliver more value to its customers. Due to SFA systems, an organization may be able to offer its customers the same services at a lower cost or maybe provide them with more information that creates more perceived value. Thus, SFA systems can help companies deliver added value to their customers.

\subsection{Individual benefits}

As seen in the previous section, SFA can provide numerous benefits to an organization. However, an SFA system also provides numerous benefits to the individual salespeople as they engage in their everyday work. For example, SFA can improve the productivity of individual salespeople, save time, and provide them with the tools they need to communicate better with their customers [10]. SFA systems can also help salespeople better understand the selling situation [7].

To determine how SFA systems affect the everyday work of salespeople, Geiger and Turley [11] decided to ask them directly. They found that salespeople felt more prepared and more confident when using an SFA tool [11]. The SFA tool made them look more professional. It also enabled them to provide their customers with more value because they could offer them more information about their previous interactions and purchases [11]. However, the salespeople also recognized a downside to using SFA in client interactions because using a laptop might be a barrier to engaging in a conversation with customers and actually listening to them [11]. Thus, SFA tools may make it possible for customers to have instant access to salespeople, so the opportunities for listening to customers in personal encounters may actually decrease [11].

Buehrer et al. [10] also interviewed salespeople about their SFA use and found that it saved them a lot of time; thus, one theme surfaced: efficiency. Ahearne et al. [12] also found that SFA tools can reduce downtime because they help salespeople plan their selling activities more efficiently giving them more time to focus on actual selling. Ahearne et al. [12] and Buehrer et al. [10] also found that SFA systems enhance salespeople's ability to communicate more clearly and more effectively with customers.

Ahearne et al. [12] also reported that salespeople can find relevant customer data more quickly and efficiently using SFA tools, putting them in a better selling position. SFA systems have been found to have a positive impact the knowledge of the sales force by aiding them in information processing [13]. Improving the market knowledge of salespeople also improves their productivity, which improves their targeting and presentation skills [13]. Ultimately, this leads to improved job performance [13].

Many studies have also investigated the relationship between the benefits gained from an SFA system and the experience and expertise of the salespeople. However, the results reported in these studies are very controversial. Mallin and DelVecchio [14] found that more experienced salespeople might see the SFA system as a burden rather than as a performance enhancer. They base their result on the fact that more experienced salespeople might be less reliant on formal means of customer communication. This means that more experienced salespeople probably need a less formal sales proposal to complete a sales transaction [14]. More experienced salespeople might also be less motivated to use a new SFA system than new salespeople [15]. In contrast, Park et al. [16] found that a salesperson's experience has a minimal impact on his/her SFA use.

Ko and Dennis [15] found that people with more experience benefit just as much from an SFA system as people with less experience, although they assumed that they would benefit less from an SFA system. This assumption is very common in the research in this area, and many studies have found that people with more experience benefit less from an SFA system. According to Ko and Dennis [15], one possible explanation for this result is that the salespeople with less experience lack the tacit and explicit knowledge to effectively apply the new knowledge from the SFA system to their sales activity. Another reason is that the SFA does not actually offer experienced salespeople any new knowledge to conduct their sales activity more effectively [15].

Holloway et al. [17] found that the relationship between ease-of-use of the system and actual SFA use becomes significantly stronger as the salesperson's experience increases. Thus, a more experienced salesperson is more likely to actually use an SFA system. To some extent, this result contradicts the results reported Ko and Dennis [15] and Park et al. [16].

Ko and Dennis [15] also studied the effect of expertise on the use of SFA systems. They found that the highest performing salespeople derived the most benefit from using an SFA system. In that study, high performers benefited up to four times more from using this tool than average performers. This result differs from the findings reported in many other studies that suggest that the highest performing salespeople gain the least from the use of an SFA system. Ko and Dennis [15] argued that this could be due to the salespeople's extensive knowledge, which they can reuse and apply through the SFA system. Another explanation could be that the salespeople with higher 
expertise are better at finding relevant information, which is actually improved with the information in the SFA system [15].

As can be seen, SFA systems offer numerous benefits to individual salespeople that can help them do their work more efficiently. SFA can help them focus more on actual selling activities and develop better relationships with their customers. This should result in greater customer satisfaction and increased sales. In many cases, this would also have an effect on a salesperson's salary as it is often based on an individual's own sales. The biggest question is: Why don't salespeople always use SFA systems if doing so might enable them to work more efficiently? Clearly the experience and expertise of the salespeople have an effect on their use of SFA systems and how much they benefit from them.

\section{Company Performance and SFA}

To understand how SFA affects a company's relationship with its customers and a firm's performance, Eggert and Serdaroglu [3] outlined two different dimensions in which SFA is used: customer relationships and internal coordination. They found that the customer relationship dimension of SFA use has a direct and significant effect on a salesperson's performance [3]. However, internal coordination only increases a salesperson's performance when he or she uses the efficiency gained from the SFA tool to engage in more effective customer relationship activities [3]. Interestingly, they also discovered that salespeople only use SFA for customer relationship activities when they are convinced that it is instrumental for increasing their performance [3].

A more recent study by Holloway et al. [17] suggested a similar point of view regarding SFA systems. They argued that the most critical issue regarding SFA systems may not be the adoption of the technology itself but the manner in which it is applied by the company's sales force. This is a result of technology becoming more common in different companies even as companies have simultaneously started to emphasize building closer customer relationships [17]. Therefore, SFA system use should be aimed at developing deeper trust-based customer relationships, which would then lead to improved sales force performance [17]. This relationship-building role of SFA has also been recognized by Boujena et al. [18].

Clearly, many researchers have identified the role of SFA in building deeper customer relationships. SFA is a tool that helps organizations develop customer relationships, which enables them to improve their performance. This was also found by Holloway et al. [17] who argued that the quality of customer relationships is critical to improving job performance. According to Holloway et al. [17], the real benefits of SFA systems come from the individual relationships that are built as a result of utilizing this tool, not from the technology itself. Their results are very similar to the findings reported in the other studies previously introduced in this section.

Hunter and Perreault [19] also conducted a study in which they assumed that sales technology has a positive effect on a salesperson's relationship-building performance. They divided sales technology use into three categories: communicating, analyzing, and accessing information. They assumed that communicating and analyzing market information would lead to sharing market knowledge with the customer and proposing integrative solutions, which would result in better relationship-building performance. They also hypothesized that all three categories would improve the salesperson's administrative performance [19].

Their findings supported their hypotheses; communicating and/or analyzing information with sales technology led to sharing market knowledge with customers and proposing integrative solutions, which resulted in better relationship-building performance. They also found that accessing and analyzing information using sales technology improved the salespeople's administrative performance. However, only using the sales technology for analyzing information may result in decreased administrative performance [19].

This viewpoint is shared by Park et al. [16], who came to the conclusion that the major benefits of an SFA system come from the system's ability to help company personnel acquire more information and shape the manner in which they sell. Thus, Park et al. [16] go a bit deeper in their analysis of how SFA use affects customer relationships. This approach is very similar to that of Holloway et al. [17]. Both studies indicated the individual learning that occurs as a result of utilizing technology is what improves performance, not the technology itself.

\section{Methods}

To explore the feature related benefits of sales configurators we developed a two-stage research design. First, to identify the possible benefits, we conducted semi-structured, in-depth personal interviews with 25 users of sales configurators. Based on the results of the interviews and the finding reported in previous literature, we designed and tested an online 
questionnaire that we administered to Finnish businessto-business (B2B) customers. The questionnaire data was analyzed and a factorial model was created. In this section, we describe the methods in detail.

\subsection{The semi-structured in-depth interviews}

The interviews were conducted at five Finnish B2B companies. The companies were selected based on the fact the companies were participating in a co-operative research project on sales configurators. When selecting the actual interview subjects, informants from the companies were asked to identify the most suitable respondents.

The interviews were designed to be semi-structured to facilitate the investigative nature of the first stage of the research. The interviews included questions about the subjects' views of sales configurators and configuration in general, the benefits of using sales configurators, the customer's decision-making process, the order-delivery process, and the role of productservice configurations.

The data set included a total of 25 interviews. Most of the interview subjects worked in their company's sales or marketing department, but a few of them worked in information system services, the production department, product support, and general management. Over $90 \%$ of the interview subjects were male. The semi-structured interviews were conducted in the spring of 2015. Most of the interviews were conducted face-to-face; however, some were conducted online using tools such as Lync or Skype. The interviews lasted from 36 to 90 minutes, and the average length of time was 60 minutes. All of the interviews were recorded and then transcribed into a digital text format by a third party.

\subsection{Online questionnaire}

An online questionnaire was targeted at Finnish B2B companies. The contact information for these companies was obtained from a national statistical agency. Over 600 companies were initially contacted by phone through their receptionists. The objective of the initial contact was to identify the most suitable responder within the company. We then phoned the identified individuals and asked about their willingness to participate in a research study that focused on SFA systems. Of the 342 representatives who indicated their willingness to respond, 152 eventually participated. This yielded a response rate of $24 \%$. The average age of the respondents was 47 . The average length of the work experience of the respondents was 18 years. Most of the respondents were male (74\%); $26 \%$ were female.
After the data collection the data was cleaned. First the data were subjected to analysis to identify inconsistencies and strange patterns. The analysis resulted in removing 19 of the responses from the final data set, mostly due to incomplete answers. Three of the 19 responses were deleted due to a repetitive answering pattern.

The online questionnaire included background questions and structured questions regarding the potential use of sales configurators. The online questionnaires were gathered in May and June of 2016.

\subsection{Model development}

As a part of the questionnaire, the respondents were presented with different benefits and characteristics associated with sales configurators. The respondents were asked to rate the benefits on a five point scale ranging from "completely meaningless" to "very important". The items were generated based on the findings reported in the previous literature [7-10] and the information obtained from the in-depth interviews.

Originally, the online questionnaire included 41 items. The items were organized into six groups (number of items in each group is denoted in parenthesis): Audiovisual elements (5), Information content (7), Navigation (8), Usability (6), Security and Reliability (6), and Configurability (9).

The study used both exploratory factor analysis (EFA) and confirmatory factor analysis (CFA) to categorize the features of a sales configurator. Using EFA and CFA in the same dataset is controversial. However, this study used CFA to confirm the results of the EFA, not to prove a theoretical construct. The preliminary EFA (Principal axis factoring with Varimax rotation) identified six factors. However, the CFA result was not acceptable $(\mathrm{CFI}=0.8, \mathrm{TLI}=0.76$ and RMSEA $=0.089$ ). The final instrument included 16 items, of which four were related to versatility, three were related to configurability, four were related to user experience, three were related to security, and two were related to customizability (Table 1). Taken together, the EFA and CFA considerably reduced the number of items (from 41 to 17). However, in comparison to the sample size (133), the initial number of items was high. Even after this pruning, the item-tosample size ratio was 1:8, which is still quite low for the CFA.

\begin{tabular}{lc}
\hline Measurement instrument & Loadings \\
\hline Versatility & \\
V1 Ability to get help online & 0.76 \\
V2 Customizable user interface & 0.76 \\
V3 Ability to get access offline & 0.67 \\
V4 Ability to use a mobile phone or tablet & 0.58
\end{tabular}


V5 Ability to use audio effects

\section{Configurability}

CO1 Price information is available

CO2 The system can automatically

recommend the product to a specific need

$\mathrm{CO} 3$ The system recalls previous purchases

and uses their information for next purchases

User experience

UE1 The system can be accessed quickly

UE2 Positive user experience

UE3 Quick and responsive features

UE4 Ease of use

\section{Security}

S1 The system is used in a secured network

S2 The system is technically reliable

S3 Information security in general

Customizability

CU1 The system works well with different

browsers

CU2 The system works well with different

operating systems

\section{Table 1. The baseline model}

Table 2 presents a summary of the CFA results. Model (M) 1 is the baseline five-factor model (Table 2). The baseline model has a good fit to the data: the chi-square test result is statistically significant, meaning that the baseline model is not a perfect fit. However, the chi-square ratio to degrees of freedom ( $\boldsymbol{\chi}^{\mathbf{2}} / \boldsymbol{d}$.f.) is 1.49 (below 2 is acceptable). The comparative fit index $(\mathrm{CFI})=.927, \mathrm{TLI}=.907$, and RMSEA $(90 \%$ CI $)=0.062(0.039 ; 0.083)$ were all acceptable.

\begin{tabular}{llllllll}
\hline $\mathbf{M}$ & $\chi^{2}$ & d.f. & $\frac{\chi^{2}}{n}$ & $\Delta \chi^{2}$ & CFI & TLI & RMSEA \\
\hline 1 & $140^{*}$ & 94 & 1.5 & & .93 & .91 & .062 \\
2 & $181^{*}$ & 98 & 1.9 & $41 *$ & .87 & .84 & .082 \\
3 & $220^{*}$ & 98 & 2.3 & $80^{*}$ & .80 & .76 & .100 \\
4 & $168^{*}$ & 98 & 1.7 & $28^{*}$ & .89 & .87 & .075 \\
5 & $194^{*}$ & 98 & 2.0 & $54^{*}$ & .85 & .81 & .088 \\
6 & $365^{*}$ & 104 & 3.5 & $224^{*}$ & .60 & .53 & .141 \\
\hline$* p<.001$ & & & & & &
\end{tabular}

\section{Table 2. CFA results}

Table 2 shows the fit of the five alternative models to the data, and it compares the alternative models with the baseline model. Both the absolute (chi-square and RMSEA) and relative (CFI and TLI) fit indices of the alternative models are below the baseline model. In addition, the chi-square difference test indicated a significantly worse fitting for the alternative models $\left(\Delta \chi^{\wedge} 2\right.$ in Table 2$)$.
Table 3 shows the mean and standard deviation of the five factors as well as the correlation between the factors. The overall correlation between the different factors is low to moderate (between .253 and .444). The highest correlation is between user experience and security (.444), user experience and reliability (.434), user experience and configurability (.415), and security and reliability (.402). Based on this, we tested the baseline model (Model 1) against four alternative models: Model 2 (user experience and security items combined), Model 3 (user experience and reliability combined), Model 4 (user experience and configurability combined), Model 5 (security and reliability combined), and Model 6 (a single factor model).

Table 3 shows the fit of the five alternative models to the data and compares the alternative models with the baseline model. Both absolute (chi-square and RMSEA) and relative (CFI and TLI) fit indices of the alternative models are below the baseline model. In addition, the chi-square difference test indicated significantly worse fitting of the alternative models $\left(\boldsymbol{\Delta} \mathcal{X}^{2}\right.$ in Table 1). The sample size was 133 and the sample-to-item ratio was 8:1.

\begin{tabular}{lcccccc}
\hline Factor & Mean & SD & 1. & 2. & 3. & 4. \\
\hline 1. Versatility & 3.4 & .73 & & & & \\
2. Configurability & 4.1 & .62 & $.25^{* *}$ & & & \\
3. User Experience & 4.6 & .39 & $.32^{* *}$ & $.42^{* *}$ & & \\
4. Security & 4.6 & .46 & $.37^{* *}$ & $.26^{* *}$ & $.44^{* *}$ & \\
5. Customizability & 4.4 & .70 & $.29^{* *}$ & $.36^{* *}$ & $.43^{* *}$ & $.40^{* *}$ \\
\hline
\end{tabular}

Table 3. Factor mean, standard deviation, and correlation between the factors

\section{Results}

The research identified five sales configurator characteristics groups: versatility, configurability, user experience, security, and customizability. A versatile sales configurator provides a set of features in addition to basic configuration capabilities. For example, a user can use audio and video elements to the enhance configuration process. In addition, the sales configurator works well with different devices, such as tablets and mobile phones. Configuration features enable a smooth configuration process. The sales configurator includes comprehensive price information and it can recommend a product based on the identified need. It also recalls previous purchases and preferences and it can recommend features based on the history data. User experience refers to the user-friendliness of a sales configurator. The sales configurator is fast and easy to use; learning how to use it is also simple. It 
offers a variety of quick and responsive functions. A secured sales configurator does not share confidential information; for example, it works in a secure network. In addition, a sales configurator is robust and technically reliable. A customizable sales configurator works with different browsers. In addition, all user interfaces are intuitive, regardless of the device.

Table 3 shows the mean and standard deviation of the different feature categories. In general, the averages are high (ranging from 3.4 to 4.6). Accordingly, the questionnaire respondents perceived all the categories as being important. However, versatility has the lowest mean and the highest standard deviation $(3.4 ; 0.73)$ and the values vary from low (1.5) to high (over 4.5). The difference between the versatility and configurability mean is also statistically significant (independent samples t-test, t-value: -9.060, p-value: 0.000). A lower mean for the versatility features is understandable because versatility features are typically additional, not mandatory. For example, some configuration processes benefit from enhanced video and audio capabilities while others do not. In addition, personal preferences vary. Some users perceive the advanced features to be useful, while others perceive them to be frustrating. All told, versatility features require special attention. They should not be developed and implemented for safety. Instead, they should be the driver for implementation. Unnecessary features may slow down and complicate the configuration process. A smooth configuration process is especially crucial in a supply chain context where a distributor may need to use a variety of sales configurators.

All the respondents considered user experience and security to be important. Actually, fewer than five respondents had a neutral attitude towards user experience and security. The rest of the respondents rated them important or very important. The high ranking for user experience is not surprising: good user experience is central to all applications, not just for sales configurators. Furthermore, in the B2B context, a customer typically uses sales configurators from several different manufacturers or sellers. In this context, simplicity, ease-of-use, and quick and responsive functions are essential. Customers do not necessarily have time to get acquainted with the features of an individual sales configurator. Instead, they need to use multiple sales configurators quickly and sufficiently. In this study, the respondents were part of B2Bs markets, where typically security is considered to be important. The products customers buy and their configuration options could be critical business information that must remain secret. Consequently, a sales configurator must work in a secure network and it must ensure information confidentiality.
The respondents also ranked configurability high (Table 2). However, the configurability mean (4.13) was less than the user experience (4.65) and security (4.62) means. In addition, the standard deviation was higher for configurability (.618 compared to .39 and .459 for user experience and security, respectively). One explanation might be that the respondents considered the configurability features (items) complementary rather than essential. However, the difference between the user experience and configurability mean was not statistically significant, and this might be due to the sampling error.

\section{Conclusions}

Previous research has found that SFA systems provide a variety of benefits to the individual user, including greater effectiveness, productiveness, and knowledgeability [10-13]. The current research adds to this by revealing that, although being productive and effective are important to an individual's success, the way in which those benefits are achieved is even more important. The current research emphasizes the importance of user experience in using SFA systems.

The goal of this research was to categorize the feature related benefits of sales configurators and to also identify the most important ones The results presented a model of the feature related benefits of sales configurators. The model was comprised of five factors: versatility, configurability, user experience, security, and customizability. Of these, the two most important factors were user experience and security. The customizability factor was found to be the least important.

The categorization of the user level benefits provides a theoretical contribution to SFA and information system literature. The results also have significant managerial implications. Companies can use the results to support better the development, implementation, and purchase of a sales configurator.

Companies can develop sales configurators with features that are relevant to the users, thus improving the performance of those individuals. Also, features that do not provide benefits can be left out or developed with only a limited effort. Again, the results give companies a tool that can be used when evaluating different operational sales configurators that have been offered to them by software companies. The results can be used in deciding which software to purchase.

The results emphasize the fact that security issues are important regarding B2B information systems. When businesses want to secure their competitive advantages, security and privacy regarding purchasing decisions are vital. 
The results contradict a typical notion that the professionalism of the B2B market customer means that the qualities they require from information systems are related to their basic functionalities. This does not mean that the basic functionalities are not important. However, we also suggest that companies emphasize the aspects of user experience when developing SFA systems.

The variance within the ratings may indicate that differences exist between different industries or user profiles so the most important benefits or features of sales configurators may differ as well. This calls for research on these topics. Can specific user profiles be identified and served better? Can specific industries benefit more from specific sales configurator functionalities? These are questions, which in our opinion deserve attention in the future.

\section{References}

[1] A. Trentin, E. Perin, and C. Forza, "Overcoming the customization-responsiveness squeeze by using product configurators: Beyond anecdotal evidence", Computers in Industry, 2011, pp. 260-268.

[2] A. Trentin, E. Perin, and C. Forza, "Sales configurator capabilities to avoid the product variety paradox: Construct development and validation", Computers in Industry, 2013, pp. 436-447.

[3] A. Eggert and M. Serdaroglu, "Exploring the Impact of Sales Technology on Salesperson Performance: A TaskBased Approach", Journal of Marketing Theory and Practice, 2011, pp. 169-186.

[4] C. Speier and V. Venkatesh, "The hidden minefields in the adoption of sales force automation technologies". Journal of Marketing, 2002, pp. 98-111.

[5] A. Trentin, E. Perin, and C. Forza, "Product configurator impact on product quality", International Journal of Production Economics, 2012, pp. 850-859.

[6] R.M. Barker, S.F. Gohmann, J. Guan, and D.J. Faulds, "Why is my sales force automation system failing?", Business horizons, 2009, pp. 233-241.

[7] L. Robinson, G.W. Marshall, and M.B. Stamps, "An empirical investigation of technology acceptance in a field sales force setting”, Industrial Marketing Management, 2005, pp. 407-415.

[8] A.J. Morgan and S.A. Inks, "Technology and the Sales Force: Increasing Acceptance of Sales Force Automation", Industrial Marketing Management, 2001, pp. 463-472.
[9] C. Pullig, J.G. Maxham, and J.F. Hair, "Salesforce automation systems: An exploratory examination of organizational factors associated with effective implementation and salesforce productivity", Journal of Business Research, 2002, pp. 401-415.

[10] R,E, Buehrer, S. Senecal, and E Bolman Pullins, "Sales force technology usage - reasons, barriers, and support: An exploratory investigation”, Industrial Marketing Management, 2005, pp. 389-398.

[11] S. Geiger, and D. Turley, "The perceived impact of information technology on salespeople's relational competencies", Journal of Marketing Management, 2006, pp. $827-851$

[12] M. Ahearne, R. Jelinek, and A. Rapp, "Moving beyond the direct effect of SFA adoption on salesperson performance: training and support as key moderating factors", Industrial Marketing Management, 2005, pp. 379388.

[13] M. Ahearne, D.E. Hughes, and N. Schillewaert, "Why sales reps should welcome information technology: Measuring the impact of CRM-based IT on sales effectiveness", International Journal of Research in Marketing, 2007, pp. 336-349.

[14] M.L. Mallin and S.K. DelVecchio, "Salesforce automation tool selectivity: an agency theory perspective", Journal of Business \& Industrial Marketing, 2008, pp. 486496.

[15] D. Ko and A.R. Dennis, "Sales force automation and sales performance: Do experience and expertise matter?", Journal of Personal Selling \& Sales Management, 2004, pp. 311-322.

[16] J.E. Park, J. Kim, A.J. Dubinsky, and H. Lee, "How does sales force automation influence relationship quality and performance? The mediating roles of learning and selling behaviors", Industrial Marketing Management, 2010, pp. 1128-1138.

[17] B.B. Holloway, G.D. Deitz, and J.D. Hansen, "The Benefits of Sales Force Automation (SFA): An Empirical Examination of SFA Usage on Relationship Quality and Performance", Journal of Relationship Marketing, 2013, pp. 223-242.

[18] O. Boujena, W.J. Johnston, and D.R. Merunka, "The benefits of sales force automation: a customer's perspective", Journal of Personal Selling \& Sales Management, 2009, pp. 137-150.

[19] G.K. Hunter and W.D. Perreault Jr, "Making sales technology effective", Journal of Marketing, 2007, pp. 16-34. 